\title{
Bearing Fault Transient Components Based on Absolute Autocorrelation Detection and Feature Expression Research
}

\author{
Ming Zhang* \\ Eastern Liaoning University, Dandong 118003, China \\ ${ }^{*}$ Corresponding author
}

\begin{abstract}
The article on the basis of analyzing the traditional autocorrelation, put forward an improvement on the transient impact composition of autocorrelation detection method, this method is able to signal the periodic transient component with more parameters. Under various faults of bearing vibration signal applications show that this method can very effectively expressed in the vibration impact characteristics, and can be conducted according to the characteristics of bearing fault diagnosis. The idea of this method is based on signal absolute value instead of the envelope calculations, so it can reduce the computational complexity, still can obtain good results.
\end{abstract}

Keywords-absolute; since the related; bearing fault; the transient; detection

\section{INTRODUCTION}

Bearings are important support parts in mechanical systems, its performance and the working condition is good or bad directly affect that goes with the rotating shaft and installed on the shaft of the gear and the performance of the whole machine equipment. According to statistics, $30 \%$ of rotating machinery fault is caused by bearing failure, the stand or fall of its great influence on the working condition of machines. Bearing defects lead to machine vibration and noise, and even cause damage to equipment. Therefore, the important use of bearing condition monitoring and fault diagnosis is very necessary ${ }^{[1]}$.

The transient components for signal detection, the most direct way is to directly determine the time domain waveform observations of the existence of a transient components, but as the transient component is usually mixed signal in noise, directly determine the accuracy of the transient components in the signal is low, the efficiency is low. Through the analysis of the power spectrum estimation is also signal the signal in the cycle characteristics of a kind of commonly used methods ${ }^{[2]}$. But for short duration of the transient characteristics of the cycle in signal, characterized by small amplitude in the power spectrum, often submerged by noise, at the same time, the transient characteristics itself is high frequency components, so the frequency of power spectrum at high frequencies and in the span is very big, through power spectrum detection often cannot get significant features.

Autocorrelation said is an effective way to detect the signal cycle of composition, but for transient signals in composition, due to the short duration, the distribution of transient components often is gaussian, so often can't get through the autocorrelation characteristic clearly.A commonly used method is to carry on the envelope autocorrelation, namely the signal envelope in the first place, and then the envelope signal autocorrelation, so it can eliminate the high frequency components in the signal frequency spectrum of signal interference, then carries on the autocorrelation or spectrum analysis, and get the signal reflect the characteristics of the periodic signal of the bearings ${ }^{[3]}$.

\section{With the BASIS OF THE ANALOG SignAL TRANSIENT IMPACT COMPONENT TESTING SIMULATION ANALYSIS}

Combining bearing fault will generally lead to the vibration of the equipment in the characteristics of the transient impact composition $^{[4,5,]}$, in mat lab in structure by the superposition of noise and periodic impact signal, periodic components of the white noise attenuation, small morel respectively two simulation analysis.

(1) $\mathrm{N}(\mathrm{t})$ is a random noise, produced by radon function in mat lab; X (t)) periodic components in the white noise attenuation. Function analytical formula for:

$$
\begin{aligned}
& n(t)=\operatorname{rand} n(t) \\
& x(t)=1.5 * \operatorname{randn}(t) * \exp \left(-\frac{t^{2}}{400}\right)
\end{aligned}
$$

(2) $\mathrm{N}(\mathrm{t})$ is a random noise, produced by radon function in mat lab; X (t)) cycle components in morlet wavelet, function analytical formula is:

$$
\begin{aligned}
& n(t)=\operatorname{rand} n(t) \\
& x(t)=3^{*} \sin (0.2 \pi t) * \exp \left(-\frac{t^{2}}{400}\right)
\end{aligned}
$$

Vibration simulation signals are: $\mathrm{y}(\mathrm{t})=\mathrm{n}(\mathrm{t})+\mathrm{x}(\mathrm{t}-\mathrm{U}), \mathrm{k}=$ $0,1,2 \ldots \mathrm{T}$ for transient component of the cycle.

For vibration simulation signal 1 , the autocorrelation, absolute autocorrelation as shown in figure1, the autocorrelation coefficient the relatively small amplitude, is not very obvious reflect the transient impact the existence of the periodic components; But its absolute phase correlation coefficient can be very clearly reflect the transient impact the existence of the periodic components. 
The simulation signal 1 polar features enhanced figure as shown in figure 2, a figure, the cycle of polar coordinates is with the letter number of cycles of the transient impact composition are equal, then the transient impact composition characterization in polar coordinates features enhance the picture just at 00 and its nearby ${ }^{[6,7]}$. Therefore, there are obvious bulge can be found in the vicinity of 00 , radius is larger.

The greater the characterization of energy; In figure b, c in the figure, the cycle of the polar coordinates and the composition of the transient impact cycles are mixed of, therefore the transient impact composition characterization of all is not as a figure in the vicinity of 00 , but scattered in the whole 3600 range, although you can see a raised spikes, but not formed near the 00 display.
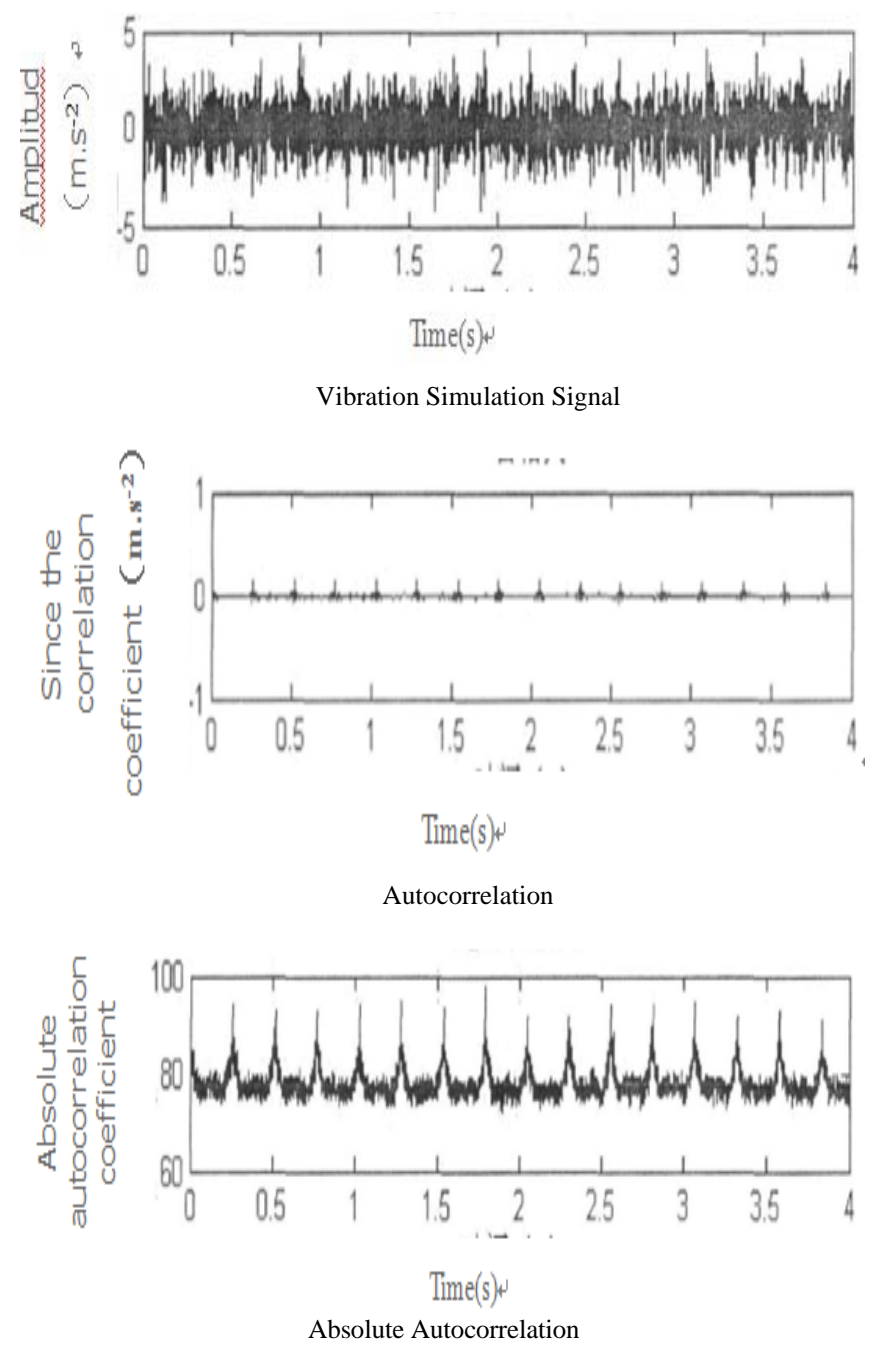

FIGURE I. THE TIME DOMAIN WAVEFORM, SIMULATION SIGNAL AUTOCORRELATION, ABSOLUTE AUTOCORRELATION.
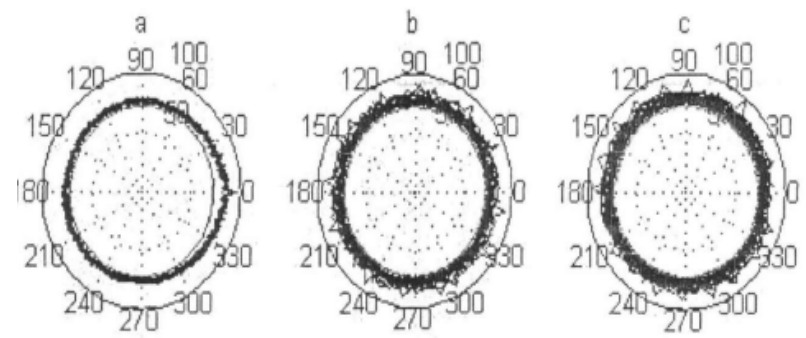

FIGURE II. SIMULATION SIGNAL 1 CHARACTERISTICS OF POLAR COORDINATES TO ENHANCE FIGURE.

\section{BEARING VIBRATION EXPERIMENT}

Bearing outer ring, inner ring and rolling element bearing fault is the main location, the injury occurred in these parts of the fault (such as local scaling and corrosion, etc.) often lead to bearing vibration in transient shock, under the condition of the bearing rotating speed is constant, exist in the cycle of the transient impact vibration signal components. However, due to local damage failure caused by vibration of short duration, at the same time, the transient impact tends to be mixed in background noise, the performance is not obvious, show the time domain signal energy increase was not significant, in frequency domain of wide frequency band, it is not easy to detect.

Subjects to install on the reducer shaft end cylindrical roller bearings, model of TMQNJ208EM, bearing the main parameters such as table 1 .

TABLE I. MAIN STRUCTURE PARAMETERS OF CYLINDRICAL ROLLER BEARING

\begin{tabular}{|c|c|c|c|c|c|}
\hline $\begin{array}{c}\text { Outer } \\
\text { radius }\end{array}$ & $\begin{array}{c}\text { Radius of } \\
\text { inner } \\
\text { ring } \\
\text { 8 }\end{array}$ & $\begin{array}{c}\text { pitch } \\
\text { diameter }\end{array}$ & $\begin{array}{c}\text { Rolling } \\
\text { body } \\
\text { straight }\end{array}$ & $\begin{array}{c}\text { A roller } \\
\text { diameter }\end{array}$ & $\begin{array}{c}\text { Contact } \\
\text { Angle for }\end{array}$ \\
\hline $80 \mathrm{~mm}$ & $40 \mathrm{~mm}$ & $60.5 \mathrm{~mm}$ & $11 \mathrm{~mm}$ & 14 & 0 " \\
\hline
\end{tabular}

Experiment was conducted under the conditions of setting fault. Respectively set bearing typical fault: Outer ring fault local, local failure and inner ring rolling body partial failure, as shown in figure 3.(a), respectively,(b), (c).

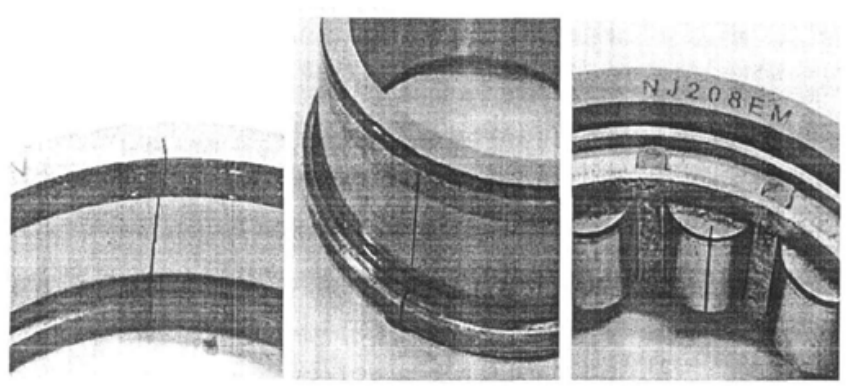

(A) Rolling bearing (B) Inner ring of the bearing (C) Rolling element failure

FIGURE III. BEARING FAULT: (A) ROLLING BEARING;(B) INNER RING OF THE BEARING;(C) ROLLING ELEMENT FAILURE 
In this case, according to the structural parameters of the bearing and the experimental speed $1496 \mathrm{r} / \mathrm{min}$, when the sampling frequency of $25.6 \mathrm{KHz}$, calculation of rolling bearing by frequency and cycle, namely the fault characteristic frequency and cycle, as shown in table $2^{[8]}$. Cycle in the table indicate that local failure occurs in the bearing outer ring, vibration signal exists in the cycle of $7.01 \mathrm{~ms}$ cycle of the transient impact composition, inside is same with local roller failure, there have cycle of $4.85 \mathrm{~ms}$ and $7.54 \mathrm{~ms}$ respectively the impact of the characteristics.

TABLE II. STRUCTURAL PARAMETERS AND KINEMATIC CHARACTERISTICS OF CYLINDRICAL ROLLER BEARING

\begin{tabular}{|c|c|c|c|c|c|}
\hline $\begin{array}{c}\text { Outer ring } \\
\text { fault } \\
\text { frequency } \\
\text { characteristic } \\
\mathrm{s}(\mathrm{Fc})\end{array}$ & $\begin{array}{c}\text { Outer ring } \\
\text { fault } \\
\text { characteris } \\
\text { tics of the } \\
\text { cycle(TC) }\end{array}$ & $\begin{array}{c}\text { The inner } \\
\text { ring fault } \\
\text { characteri } \\
\text { stic } \\
\text { frequency } \\
\text { (Fi) }\end{array}$ & $\begin{array}{c}\text { The inner } \\
\text { ring fault } \\
\text { characteris } \\
\text { tics of the } \\
\text { cycle(Ti) }\end{array}$ & $\begin{array}{c}\text { Rolling } \\
\text { element } \\
\text { fault } \\
\text { characteris } \\
\text { tic } \\
\text { frequency( } \\
\text { Fe) }\end{array}$ & $\begin{array}{c}\text { Rolling } \\
\text { element } \\
\text { fault } \\
\text { characteris } \\
\text { tics of the } \\
\text { cycle(Te) }\end{array}$ \\
\hline $142.57 \mathrm{HZ}$ & $7.01 \mathrm{~ms}$ & $206.20 \mathrm{HZ}$ & $4.85 \mathrm{~ms}$ & $132.56 \mathrm{HZ}$ & $7.56 \mathrm{~ms}^{2}$ \\
\hline
\end{tabular}

This $\bar{x}=|x(t)|$ experiment using $\mathrm{k}=0$ time average function, signal length $\mathrm{N}=\mathrm{L} / 10$ autocorrelation detection method, collection of bearing outer ring, inner ring, rolling body partial failure and failure both exist at the time of the vibration signal analysis, fault characteristic frequency is calculated, and the correlation coefficient of polar coordinates.

\section{THE EXPERIMENT RESULtS ANALYSIS}

Figure 2 for bearing the analysis results of normal state diagram. Figure $2(\mathrm{a}) \mathrm{x}(\mathrm{t})$ for the acquisition of vibration signal waveform, largely in line with random noise, but not qualitative quantitative analysis. Figure 2 (b) is the absolute value of vibration signal. Figure 2 (c) is calculated from the correlation coefficient $\mathrm{R}$ a (z) waveform, correlation coefficients can be seen from the figure in the RX (about basic remain constant, constant reflects the noise level. The correlation coefficient of the Fourier transform of frequency spectrum as shown in figure 2 (a), in addition to containing some noise outside, does not contain any fault feature frequency components. Figure 2 for the autocorrelation coefficient under the normal r.. (R) on the outer ring fault features period $\mathrm{T}$, the inner ring fault weeks $\mathrm{T}$, and the characteristics of rolling element failure period $\mathrm{T}$ under polar coordinate transformation enhanced results. From the figure a, b,. It can be seen that in the normal state of the autocorrelation coefficient R.r (z) in the three cycles, the fault features are characterized by very good circular ring effect, and not in a bulge or burr phenomenon appears on the characteristic frequency, objectively illustrates the bearing is not failure, but keep a good state of normal operation ${ }^{[9]}$.

\section{CONCLUSION}

As can be seen from the experimental results, the bearing under normal working condition, the vibration signal is more close to the random noise. When a bearing failure ${ }^{[8]}$, there will always be new frequency components of the signal, with the degree of fault, the frequency components of the energy will be more more, made by the test analysis methods in this chapter. As long as there is some kind of fault feature frequency components, in the energy under the condition of not completely submerged by background noise, using this method can be a good characterization of the fault characteristics.

Article proposed cycle detection method of the transient components, is to use the sensor input and $d / a$ conversion, signal $\mathrm{x}(\mathrm{t})$, signal $\mathrm{x}(\mathrm{t})$ whether there is a cycle in the transient components ${ }^{[10]}$. Its features include the following steps: calculating signal time average function of $x(t)$;Calculate the correlation coefficient; Fast Fourier transform is used to calculate the spectrum of households according to spectrum signal of main frequency components ${ }^{[10]}$. Respectively according to cycle, polar mapping, and the mapping on the polar diagram, when the corresponding to the cycle of Tn $(1<$ _n $<$ m) enhanced features to appear on the polar plot, said to determine whether there is a cycle in the signal to be detected for no, transient components. And use the set bearing failure experiment has carried on the inspection, test results show that the proposed method is simple to implement the transient components characteristic parameters and adaptive testing cycle, improved the efficiency of the cycle of judgment and accuracy; Especially suitable for rotating machinery fault automatic identification, fault and can successfully to exist at the time of diagnosis.

\section{REFERENCES}

[1] Boas hash B, O Shea P. Polynomial Wigner-Ville Distributions and Their Relationship to Time-Varying Higher Order Spectra. IEEE Transactions on Signal Processing. 1994

[2] Velez E F, A bashers R G. Smoothed Wigner-Ville Parametric Modeling for the Analysis of No stationary Signals. IEEE International Symposium on Circuits and Systems. 1989

[3] Velez E F, Asher R G. Transient analysis of speech signals using the Wigner time-frequency representation. ICASSP-89. 1989

[4] T. Kaewkongka, Y. H. J. Au, R. T. Rakowski, B. E. Jones. A comparative study of short time Fourier transform and continuous wavelet transform for bearing condition monitoring. Int. J. Comdex. 2003

[5] Ramie, M.A Rafiee, P. W. Tse. Application of mother Wavelet functions for automatic gear and bearing fault diagnosis. Expert Systems With Applications. 2010

[6] D. Pines, L. Salvino. Health monitoring of one dimensional structure using empirical mode decomposition and the Hilbert-Huang transform. SPIE Proceeding. 2002

[7] S. Ikeda, K. Toyama. Independent Component Analysis for Noisy Data-MEG Data Analysis. Neural Networks. 2000

[8] Xu YG ,Wang TY, Lang YG, et al. Fault feature extraction of mechanical equipments based on ICA and HHT. 9th World Multi-Conference on Systemic, Cybernetics and Informatics. 2005

[9] G. Gelle, M. Colas. Blind sources separation: A tool for rotating machine monitoring by vibrations analysis. Journal of Sound and Vibration. 2001

[10] J. Antonio. The spectral kurtosis: a useful tool for characterizing no stationary signals. Journal of Mechanical Systems. 2006 